\title{
ANALISIS PENDAPATAN USAHA TERNAK BABI DI KECAMATAN TOMBULU KABUPATEN MINAHASA
}

\author{
Yudi P. Sinulingga, NM Santa*, LS Kalangi, MAV Manese \\ Fakultas Peternakan Universitas Sam Ratulangi, 95115
}

\begin{abstract}
ABSTRAK
Penelitian dilaksanakan di Kecamatan Tombulu Kabupaten Minahasa selama satu bulan dari bulan Januari 2020 sampai Februari 2020. Data yang digunakan dalam penelitian ini yaitu data primer dan data sekunder. Penentuan lokasi sampel di Kecamatan Tombulu menggunakan metode Puposive Sampling dengan jumlah peternak yang ada di Kecamatan Tombulu ada 30 peternak. Penentuan sampel menggunakan teknik Total Quota Sampling. Model usaha ternak babi yang dijalankan oleh peternak yaitu pembibitan, penggemukan, kombinasi, dan babi putar. Hasil penelitian menunjukkan model usaha ternak babi di Kecamatan Tombulu yang dominan adalah kombinasi dari pembibitan dan penggemukan. Pendapatan yang diperoleh dari usaha ternak babi sebesar Rp39.207.785/periode atau Rp3.920.778/bulan. Jumlah produksi, biaya pakan, dan biaya sosial adalah faktor-faktor yang sangat berpengaruh pada pendapatan usaha ternak babi.
\end{abstract}

Kata kunci : pendapatan, ternak babi, faktor-faktor

\section{ABSTRACT}

ANALYSIS OF PIG LIVESTOCK BUSINESS INCOME IN TOMBULU DISTRICT MINAHASA REGENCY. The study was conducted in the Tombulu District of Minahasa Regency for one month from January 2020 to February 2020.

*Korespondensi (corresponding author): Email: nansisanta@unsrat.ac.id
The data used in this study were primary data and secondary data. The puposive sampling method was applied to determine the sample location in Tombulu District with the number of breeders in Tombulu District were 30 breeders. Therefore, the determination of the sample applied Total Quota Sampling technique. Pigs livestock business models run by breeders were breeding, fattening, combination, and swine pigs. The result showed models that the dominant pig livestock business in Tombulu District was a combination of breeding and fattening. The income earned from the pig livestock business is Rp.39,207,785 / period or Rp3,920,778 / month. The amount of production, feed costs, and social costs are factors that were very influential on the business income of pig livestock.

Key words: income, pig livestock, factors

\section{PENDAHULUAN}

Ternak babi merupakan jenis ternak yang mampu menghasilkan daging dalam kurun waktu yang relatif singkat. Ternak babi tergolong dalam ternak monogastrik dimana memiliki kemampuan dalam mengubah bahan makanan secara efisien apabila ditunjang dengan kualitas ransum yang dikonsumsinya. Selain kemampuan ternak babi dalam mengkonversi pakan menjadi daging yang 
cepat, ternak babi juga merupakan ternak yang prolifik yaitu mampu melahirkan anak 10-14 ekor dalam satu periode melahirkan (Sihombing, 1997).

\section{Kabupaten Minahasa Propinsi}

Sulawesi Utara memiliki populasi ternak babi yang paling tinggi berdasarkan data Badan Pusat Statistik Propinsi Sulawesi Utara tahun 2017 dengan jumlah sebanyak 126.157 ekor. Berdasarkan hasil penelitian (Santa dan Wantasen 2018), usaha peternakan babi masyarakat pedesaan di Kabupaten Minahasa, melaksanakan 3 (tiga) model usaha yaitu pembibitan, penggemukan dan usaha kombinasi. Pemeliharaan ternak dengan cara semi intensif yaitu ternak babi dipelihara dikandang yang sudah terbuat dari beton baik dinding kandang maupun lantai (Kojo et al., 2014).

Peternak babi di Kecamatan Tombulu mendirikan usahanya dekat dengan pemukiman penduduk sehingga memberikan dampak negatif kepada masyarakat sekitar. Dampak negatif dari usaha ternak babi yakni bau busuk dar fases dan urine dan kotoran ternak babi yang langsung dibuang ke sungai. Fases dan Urin dari ternak babi tidak bisa digunakan sebagai pupuk untuk semua jenis tanaman dikarenakan alasan keamanan pangan, sehingga peternak hanya membuang kotoran ternanknya ke sungai. Hal tersebut membuat warga melakukan protes terhadap usaha ternak babi yang ada di Kecamatan Tombulu dan berdampak terhadap ancaman penutupan usaha ternak babi. Sehingga solusi alternatif yang dilakukan adalah membayar sejumlah uang dispensasi dalam bentuk biaya sosial agar usaha mereka tidak di tutup oleh warga. Uang yang dibayarkan tersebut nantinya akan digunakan untuk mendukung acara rutin tahunan seperti natal, pengucapan syukur, paskah, hari kemerdekaan, dan lain-lainnya. Dengan rutinnya mengeluarkan biaya sosial yang dukeluarkan tentunya akan memiliki pengaruh terhadap pendapatan yang diterima oleh peternak.

Peternak babi di Kecamatan Tombulu masih menggunakan pakan pabrikan atau pakan komersial yang diperoleh peternak dengan membeli pakan di toko khusus menjual pakan ternak. Keadaan tersebut menyebabkan biaya produksi usaha ternak babi akan meningkat seiring dengan peningkatan harga pakan dan mengakibatkan jumlah pendapatan peternak akan menurun. Menggunakan pakan alternatif atau pakan non-konvensional mungkin menjadi salah satu solusi agar dapat menekan harga pakan. Contoh pakan alternatif seperti batang pohon pisang, dedak padi, dan polar ketersediaannya berlimpah dan mudah diperoleh (Sukanata et al., 2014); (Sukanata et al., 2017). 
Usaha ternak babi merupakan usaha yang potensial untuk dikembangkan khususnya di Kecamatan Tombulu Kabupaten Minahasa. Namun terdapat faktor-faktor yang berpengaruh terhadap pendapatan usaha ternak babi. Faktorfaktor tersebut antara lain biaya pakan, jumlah produksi, jumlah anggota keluarga, biaya tenaga kerja, dan biaya sosial dimana belum diketahui sejauh mana pengaruhnya pada pendapatan usaha ternak babi di Kecamatan Tombulu

Karena itu tujuan dari penelitian ini yaitu untuk menganalisis jumlah pendapatan usaha ternak babi serta untuk menganalisis faktor-faktor yang mempengaruhi pendapatan usaha ternak babi.

\section{METODE PENELITIAN}

\section{Tempat dan Waktu Penelitian}

Lokasi penelitian dilaksanakan di Kecamatan Tombulu Kabupaten Minahasa selama satu bulan dari bulan Januari 2020 sampai Februari 2020.

\section{Jenis dan Sumber Data}

Data yang digunakan dalam penelitian ini yaitu data primer dan data sekunder. Data primer merupakan hasil pengamatan dan hasil wawancara terhadap peternak sebagai responden. Data sekunder berupa data dari BPP Kecamatan
Tombulu, Badan Pusat Statistik serta jurnal yang berkaitan dengan penelitian.

\section{Metode Penentuan Sampel}

Penentuan lokasi sampel di Kecamatan Tombulu menggunakan metode Purposive Sampling (Sugiyono, 2010), berdasarkan pertimbangan bahwa Kecamatan Tombulu strategis karena dekat dengan Kota Manado sebagai Ibukota Propinsi Sulawesi Utara, serta memiliki peternak babi . Hasil pra-penelitian menunjukkan bahwa jumlah peternak yang ada di Kecamatan Tombulu ada 30 peternak.

Berdasarkan data dari BPP Kecamatan Tombulu jumlah peternak babi di Kecamatan Tombulu ada sebanyak 30 orang, sehingga penentuan sampel menggunakan teknik Total Quota Sampling, dengan pertimbangan bahwa jumlah peternak babi sudah memenuhi syarat untuk dijadikan sampel (Sugiyono, 2010).

\section{Model Analisis}

1. Tujuan pertama penelitian ini yaitu untuk mengetahui jumlah pendapatan usaha ternak babi, dianalisis menggunakan persamaan berikut (Soekartawi, 2002):

$$
\mathrm{Pd}=\mathrm{TR}-\mathrm{TC}
$$

Keterangan:

$\mathrm{Pd}=$ pendapatan bersih

$\mathrm{TR}=$ penerimaan

$\mathrm{TC}=$ total biaya 
2. Tujuan kedua penelitian ini yaitu untuk menganalisis faktor-faktor yang mempengaruhi pendapatan usaha ternak babi, menggunakan persamaan berikut.

$$
\begin{aligned}
& Y=a+b_{1} X_{1}+b_{2} X_{2}+b_{3} X_{3}+b_{4} X_{4}+b_{5} X_{5} \\
& +e
\end{aligned}
$$

Keterangan:

$\mathrm{Y} \quad=$ Pendapatan peternak babi (Rp/periode)

$$
\begin{array}{ll}
\mathrm{a} & =\text { konstanta } \\
\mathrm{b} 1, \ldots, \mathrm{b} 5 & =\text { Koefisien regresi } \\
\mathrm{X}_{1} & =\text { jumlah produksi (Kg/periode) } \\
\mathrm{X}_{2} & =\text { biaya tenaga kerja (Rp/periode) } \\
\mathrm{X}_{3} & =\text { biaya pakan (Rp/periode) } \\
\mathrm{X}_{4} & =\text { jumlah anggota keluarga } \\
\mathrm{X}_{5} & \text { (orang) } \\
\mathrm{e} & =\text { biaya sosial (Rp/periode) }
\end{array}
$$$$
\text { Menurut (Winarno, 2015) uji }
$$

statistik $\mathrm{F}$ untuk mengetahui pengaruh variabel bebas (jumlah produksi, biaya tenaga kerja, biaya pakan, jumlah anggota keluarga, dan biaya sosial) secara bersama-sama terhadap variabel terikat (pendapatan peternak babi). Hipotesis nol adalah jenis joint hypothesis bahwa b1, b2,..,bk secara simultan sama dengan nol (Winarno, 2015).

1. Jika F-hitung > F-Tabel, maka tolak H0, artinya variabel independen (jumlah produksi, biaya tenaga kerja, biaya pakan, jumlah anggota keluarga, dan biaya sosial) berpengaruh nyata terhadap variabel dependen (pendapatan).

2. Jika F-hitung < F-Tabel, maka terima H0, artinya variabel independen (jumlah produksi, biaya tenaga kerja, biaya pakan, jumlah anggota keluarga, dan biaya sosial) tidak berpengaruh nyata terhadap variabel dependen (pendapatan).

Uji statistik $\mathrm{t}$ digunakan untuk mengetahui peran masing-masing variabel bebas (Winarno, 2015) (jumlah produksi, biaya tenaga kerja, biaya pakan, jumlah anggota keluarga, dan biaya sosial) secara parsial terhadap variabel terikat (pendapatan peternak babi).Misalnya ingin menguji apakah X1 berpengaruh terhadap Y dengan menganggap $\mathrm{X}$ lainnya konstan:

1. Jika t-hitung > t-tabel, maka tolak H0, artinya variabel independen (jumlah produksi, biaya tenaga kerja, biaya pakan, jumlah anggota keluarga, dan biaya sosial) berpengaruh nyata terhadap variabel dependen (pendapatan).

2. Jika t-hitung $<\mathrm{t}$-tabel, maka terima H0, artinya Variabel independen (jumlah produksi, biaya tenaga kerja, biaya pakan, jumlah anggota keluarga, dan biaya sosial) tidak berpengaruh nyata terhadap variabel dependen (pendapatan).

Dimana b1 adalah koefisien parameter dan se (b1) adalah standart error koefisien 
parameter. Jika nilai $\mathrm{t}$ hitung $>$ nilai $\mathrm{t}$ Tabel $t a(n-k)$, maka H0 ditolak yang berarti X1 bepengaruh terhadap Y.

\section{HASIL DAN PEMBAHASAN}

\section{Keadaan Umum Wilayah Kecamatan Tombulu}

Kecamatan Tombulu merupakan salah satu kecamatan yang berbatasan dengan Kota Manado serta kota Tomohon. Ada pun batas-batas secara administrasi wilayah Kecamatan Tombulu sebagai berikut:

Sebelah Utara dengan Laut Sulawesi

Sebelah timur dengan Kecamatan

Tondano Barat

Sebelah selatan dengan Kecamatan

Pineleng dan Kota Tomohon

Sebelah barat dengan Kabupaten Minahasa Utara

Kecamatan Tombulu memiliki wilayah yang membentang seluas 97,4 $\mathrm{km}^{2}$ dan terletak pada $0,35^{\prime}-1,01^{\prime} \mathrm{LU}$ dan $124,25^{\prime}-124,37^{\prime}$.

\section{Karakteristik Responden}

Hasil penelitian diperoleh variasi umur peternak babi di kecamatan Tombulu, yaitu antara 37-72 Tahun. Dengan umur 35-44 terdapat 26,66\%, umur 45-54 terdapat 36,66\% , umur 55-64 terdapat $23,33 \%$, dan umur 65-74 terdapat $13,33 \%$.
Tingkat pendidikan peternak yang paling tinggi Sarjana dan terendah TK. Tingkat pendidikan peternak di Kecamatan Tombulu bervariasi dengan tingkat pendidikan paling banyak yaitu SLTA sebesar 46,66\%, lalu SMP dan Perguruan Tinggi masing-masing sebesar 20\%, serta SD sebesar $10 \%$, dan TK sebesar 3,33\%.

Hasil penelitian menunjukkan banyak peternak babi di Kecamatan Tombulu yang menjadikan beternak babi sebagai pekerjaan sampingan. Sebanyak $66,66 \%$ peternak babi di kecamatan Tombulu adalah sebagai pekerjaan sampingan dengan mayoritas pekerjaan utama sebagai petani. Sedangkan 33,33\% peternak babi di Kecamatan Tombulu menjadikan beternak babi menjadi pekerjaan utama mereka.

\section{Karakteristik Usaha Ternak Babi}

\section{Lama Usaha}

Sebanyak $66,66 \%$ peternak babi yang ada di Kecamatan Tombulu merupakan peternak yang telah melakukan usaha selama 1-10 tahun, sebanyak 20\% peternak telah melakukan usaha ternak babi sebanyak 11-20 tahun, dan 13,33\% peternak yang sudah melakukan usaha diatas 20 tahun. Namun sebernarnya peternak yang melakukan usaha 1-10 tahun tersebut mayoritas merupakan peternak yang sudah pernah melakukan usaha ternak babi namun berhenti 
dikarenakan beberapa faktor seperti, harga pakan yang mahal, rendahnya nilai jual ternak, penyakit, dan modal yang kurang.

\section{Jumlah Induk dan Anak Babi}

Sebanyak 20 orang peternak yang memiliki induk babi sendiri dengan jumlah induk antara 2-15 ekor. Sebanyak 13 pejantan dari 11 peternak dengan jumlah pejantan 1-3 ekor per peternak. Usaha ternak babi pembibitan memiliki jumlah induk yang lebih banyak dari usaha ternak babi penggemukan.

\section{Manajemen Pemeliharaan Ternak Babi}

Hasil dilapangan usaha ternak babi yang ada di Kecamatan Tombulu hampir semua dikelola oleh kepala keluarga seorang diri. Menejemen pemeliharaan ternak babi di Kecamatan Tombulu dilakukan dengan memberi makan pada pagi dan sore hari. Pemberian pakan pada ternak babi dilakukan tanpa penakaran jumlah pakan yang diberikan, sehingga sulit melihat jumlah kenaikan bobot badan dari jumlah pakan yang diberikan. Mayoritas responden yang ada di Kecamatan Tombulu membeli pakan komersial (konsentrat, jagung, dan dedak padi).

Perkandangan ternak babi di Kecamatan Tombulu umumnya dilakukan dekat pemukiman dan dekat dengan sumber air. Namun ada beberapa peternak yang melakukan usaha ternak babi jauh dari sumber air dan pemukian. Tipe kandang yang digunakan adalah tipe kelompok dan individu dengan rata-rata panjang dan lebar yakni $3 \times 4 \mathrm{~m}$ untuk setiap kandang.

Sistem perkawinan ternak babi di Kecamatan Tombulu masih menggunakan sistem perkawinan alami. Banyak peternak masih belum tahu dan ragu dalam menggunkan sistem perkawinan IB karena masih rendahnya pengetahuan tentang IB dan mahalnya peralatan yang dibutuhkan. Tingkat mortalitas ternak babi di Kecamatan Tombulu terbilang rendah karena rata-rata sebesar 5\% dan mayoritas faktor penyebab kematian yakni ditindih induk, mencret, berkelahi, dan gangguan hewan liar.

Kegiatan peternak yang dilakukan di peternakan yakni membersihan kandang, memandikan ternak, memberikan pakan, memisahkan induk dengan anak untuk dilakukan pembersihan, dan pengecekan anak-anak babi. Lama waktu yang digunakan oleh peternak babi selama dikandang berkisar antara 2- 3 jam/hari tergantung jumlah ternak dan jenis usaha yang dilakukan. Sesuai dengan (Kojo, et al., 2014) rata-rata curahan waktu dikandang adalah sebesar 3 jam/hari. Aktivitas dikandang dilakukan sebanyak 2 kali dalam satu hari yakni pagi dan sore hari, dengan waktu berkisar dari jam 7 hingga 9 untuk pagi hari dan dan 4 sampai 5 di sore hari. 


\section{Model Usaha Ternak Babi di Kecamatan Tombulu}

Jenis usaha yang dilakukan oleh peternak babi di Kecamatan Tombulu yaitu pembibitan, penggemukan, campuran (pembibitan dan penggemukan), dan babi putar. Jenis yang paling banyak adalah usaha kombinasi (pembibitan dan penggemukan) karena dapat menyesuaikan dengan harga pakan. Bila harga pakan naik maka peternak akan mengurangi jumlah ternak babi yang dipelihara dengan menjual babi usia starter.

Penjualan ternak babi akan dilakukan oleh peternak jika target pemeliharaan sudah tercapai yakni umur 45 hari untuk usaha pembibitan, berat 100 $\mathrm{kg}$ untuk usaha pengemukan, dan berat 30 kg untuk usaha babi putar. Penentuan harga untuk ternak babi hampi semua mengikuti harga pasar, namun untuk peternak yang sudah memiliki langganan harga ternak babi cenderung lebih stabil jika dibandingkan dengan peternak babi yang tidak memiliki langganan.

\section{Pendapatan Usaha Ternak Babi di Kecamatan Tombulu}

Pendapatan merupakan selisih antara penerimaan dengan semua biaya yang dikeluarkan. Jumlah penerimaan usaha ternak babi yaitu jumlah produksi ternak babi dikali dengan harga berat hidup.

Berdasarkan Tabel 1 diketahui bahwa penerimaan yang diperoleh peternak berasal dari modal yang dimiliki berupa induk dan pejantan, penjualan anak babi dan penjualan babi penggemukan.

Tabel 1. Penerimaan dan Pengeluaran Usaha Ternak Babi

\begin{tabular}{|c|c|c|c|}
\hline No & Uraian & $\begin{array}{c}\text { Jumlah } \\
\text { (Rp/Periode) }\end{array}$ & Persentase $(\%)$ \\
\hline \multirow[t]{5}{*}{1} & Penerimaan & & \\
\hline & 1) Modal (induk dan pejantan) (ekor) & 35.545 .263 & 40,3 \\
\hline & 2) Penjualan Anak Babi (ekor) & 1.128 .333 & 1,3 \\
\hline & 3) Penjualan babi penggemukan $(\mathrm{kg})$ & 51.636 .667 & 58,4 \\
\hline & Total Penerimaan & 88.310 .263 & 100 \\
\hline \multirow[t]{10}{*}{2} & Pengeluaran & & \\
\hline & Biaya Tetap: & & \\
\hline & 1) Penyusutan Kandang & 1.550 .000 & 3,1 \\
\hline & Biaya Tidak Tetap: & & \\
\hline & 1) Biaya Tenaga Kerja & 5.200 .000 & 10,6 \\
\hline & 2) Biaya Pakan & 29.291 .872 & 59,7 \\
\hline & 3) Biaya Pembelian Bibit & 11.727 .273 & 23,9 \\
\hline & Baiya lain & & \\
\hline & 1) Biaya Sosial & 1.333 .333 & 2,7 \\
\hline & Total Biaya & 49.102 .478 & 100 \\
\hline
\end{tabular}


Penerimaan usaha ternak babi berasal dari modal yang dimiliki berupa induk dan pejantan, penjualan anak babi, dan penjualan babi finisher. Penjualan dari modal merupakan hasil perkalian antara jumlah induk dan pejantan yang dimilki peternak dikali dengan bobot badan, dan harga berat hidup ternak babi. Penerimaan dari penjualan anak babi yakni perkalian antara jumlah anak babi umur 45 hari dengan harga dengan rata-rata yakni Rp800.000/ekor. Penerimaan yang berasal dari penjualan babi finisher merupakan hasil perkalian antara berat hidup dengan harga hidup. Jenis biaya tetap dan biaya tidak tetap pada usaha ternak babi di Kecamatan Tombulu, dijelaskan pada tabel 1.

\section{Faktor-faktor yang Mempengaruhi Pendapatan Usaha Ternak Babi}

Berdasarkan hasil regresi dapat diketahui nilai konstanta / intercept adalah sebesar 11.578.875, artinya apabila variabel bebas yaitu jumlah produksi, biaya pakan, biaya tenaga kerja, jumlah anggota keluarga, dan biaya sosial tak berubah maka peternak babi akan menerima pendapatan sebesar nilai konstanta yakni Rp11.578.875/periode. RSquare bernilai 95\%, artinya bahwa semua variabel idependen (jumlah produksi, biaya pakan, biaya tenaga kerja, jumlah anggota keluarga, dan biaya sosial) yang dapat mempengaruhi pendapatan peternak babi sebesar $95 \%$ dan selebihnya yaitu sebesar 5\% dijelaskan oleh variabel yang tidak diteliti oleh peneliti. Nilai probabiltas F-hitung sebesar 0,00 hal ini menunjukkan bahwa secara bersama-sama semua variabel bebas yakni jumlah produksi, biaya pakan, biaya tenaga kerja, jumlah anggota keluarga, dan biaya sosial berpengaruh nyata terhadap pendapatan ternak babi.

Pengujian terhadap penyimpangan asumsi klasik telah dilakukan untuk data saat ini. Hasil pengujian menunjukkan bahwa tidak terdapat penyimpangan asumsi klasik khusunya multikolinearitas yang ditunjukkan nilai R-Square yang tinggi dengan rendahnya jumlah variabel yang tidak signifikan.

\section{Jumlah Produksi}

$$
\text { Variabel jumlah produksi }
$$

berpengaruh sangat nyata terhadap pendapatan dengan nilai probabilitas jumlah produksi sebesar $0,00<0,01$, jika diukur dengan tingkat kepercayaan 99\% dan angka koefisien 35.266. Sifat hubungan dari koefisien regresi berganda positif berarti setiap bertambanhnya jumlah produksi sebesar $1 \mathrm{~kg}$, maka peternak menerima peningkatan pendapatan sebesar Rp35.266. Jumlah produksi ternak babi dihitung dari jumlah anak, induk, dan pejantan kemudian dikali dengan berat hidup. Jumlah produksi tidak terlepas dari jumlah induk babi yang 
Tabel 2. Hasil Analisis Regresi Faktor-faktor Yang Mempengaruhi Pendapatan Usaha Ternak Babi.

\begin{tabular}{lcr}
\hline \multicolumn{1}{c}{ Variabel } & TH & Koefisien \\
\hline Konstanta & & $11.578 .875,00$ \\
JumlahProduksi & + & $35.266,71 * * *$ \\
BiayaPakan & - & $-1,53 * * *$ \\
BiayaTenagaKerja & - & 0,23 \\
BiayaSosial & - & $-14,23 * * *$ \\
Jumlah Anggota & - & $169.599,70$ \\
Keluarga & & 0,95 \\
R-squared & & 106,84 \\
F-hitung & &
\end{tabular}

dimiliki oleh peternak karena semakin banyak jumlah induk maka jumlah anak yang dilahirkan juga akan semakin banyak, jumlah induk dan anak ternak babi. Jumlah induk yang dimiliki oleh peternak bevariasi tergantung tujuan pemeliharaan, untuk tujuan pemeliharaan pembibitan jumlah induk lebih banyak dari pada jumlah induk kombinasi dan penggemukan. Hal ini sesuai menurut (Pardede, 2015); (Santa dan Wantasen 2018) bahwa jumlah pemilikan ternak berpengaruh nyata terhadap pendapatan.

\section{Biaya Pakan}

Variabel biaya pakan berpengaruh sangat nyata terhadap pendapatan peternak dengan nilai probabilitas biaya pakan sebesar $0,00<0,01$, jika diukur dengan tingkat kepercayaan $99 \%$ dan angka koefisien -1,53. Sifat hubungan dari koefisien regresi bertanda negatif, berarti setiap kenaikan biaya pakan sebesar Rp1.000 maka akan mengurangi pendapatan peternak sebesar Rp1.530,- per-periode. Biaya pakan yang tinggi juga disebabkan oleh peternak yang belum memanfaatkan pakan alternatif dan masih bergantung pada pakan komersial seperti jagung, konsentrat, dan dedak padi dimana ketiga komuditi ini mengalami kenaikan harga pada awal tahun 2020 sehingga membuat biaya pakan meningkat. Hal ini sesuai menurut (Wunda et al., 2014); (Sadhu et al., 2018) (Sarajar et al., 2019) bahwa biaya pakan berpengaruh nyata terhadap pendapatan peternak.

\section{Biaya Sosial}

Variabel biaya sosial berpengaruh sangat nyata terhadap pendapatan peternak nilai probabiliti biaya sosial sebesar 0,009 $<0,01$, jika diukur dengan tingkat kepercayaan 99\% dan angka koefisien 14,23. Sifat hubungan dari koefisien regresi bertanda negatif berarti setiap mengeluarkan biaya sosial sebesarRp1.000 maka pendapatan peternak berkurang sebesar Rp14.230. Hal ini dikarenkan peternak di Kecamatan Tombulu 
mendirikan usaha mereka dekat dengan pemukiman penduduk sehingga dampak negatif dari usaha ternak babi dirasakan langsung oleh masyarakat. Dampak negatif tersebut antara lain bau busuk dari kotoran ternak babi dan sungai yang tercemar kotoran ternak. Sehingga warga mendesak agar usaha ternak babi di Kecamatan Tombulu ditutup, keadaan ini membuat Pemerintah yang ada di Kecamatan Tombulu memberikan solusi yaitu dengan membayarkan sejumlah uang untuk kegiatan sosial. Kegiatan-kegiatan tersebut antara lain hari kemerdekaan, natal, tahun baru, pengucapan syukur, paskah, dan kegiatan lainnya. Jumlah biaya sosial yang diberikan peternak juga dipengaruhi oleh skala usaha yang dijalankan oleh peternak, jika usaha semakin besar maka sumbangan yang diberikan akan semakin besar pula.

\section{KESIMPULAN}

Usaha ternak babi di Kecamatan Tombulu yang dominan adalah kombinasi dari pembibitan dan penggemukan. Pendapatan yang diperoleh dari usaha ternak babi sebesar Rp39.207.785/periode atau Rp3.920.778/bulan. Jumlah produksi, biaya pakan, dan biaya sosial adalah factor-faktor yang sangat berpengaruh pada pendapatan usaha ternak babi.

\section{DAFTAR PUSTAKA}

Badan Pusat Sulawesi Utara, 2018. Populasi Ternak di Kabupaten Minahasa 2017

Kojo, R. E., V. V. J. Panelewen, M. A. V. Manese, dan Nansi M. Santa. 2014. Efisiensi penggunaan input pakan dan keuntungan pada usaha ternak babi di Kecamatan Tareran Kabupaten Minahasa Selatan. Zootec 34 (1): 62-74.

Mulya, B. G., Hasnudi, dan U. Budi. 2013. Analisis profil peternak terhadap pendapatan peternak babi di Kecamatan Lintong Nihuta Kabupaten Humbang Hasundutan. Peternakan Integratif 01 (2) : 100-113.

Pardede, S. 2015. Analisis biaya dan keuntungan usaha peternakan babi rakyat di desa cigugur, kecamatan cigugur, kabupaten kuningan jawa barati. Ilmu ternak 04 (3) : 01-06.

Santa N. M. dan E. Wantasen. 2018. Profit Analysis Of Pig Farming In Rural Comunities In Minahasa Regency Of North Sulawesi. JITAA 43(3) :289-295.

Sarajar, M.J., F.H. Elly, E. Wantasen, dan S.J.K. Umboh. 2019. Analisis Usaha Ternak Babi di Kecamatan Sonder Kabupaten Minahasa. Zootec 39 (2): 276 -283.

Sadhu, A. T. T., N. W. T. Inggriati, dan N. Suparta. 2018. Hubungan antara Penerapan Panca Usaha Peternakan Babi Dengan Tingkat Pendapatan Peternak Plasma pada Pola Kemitraan PT. Charoen Pokphand di Bali. Journal of Tropical Animal Science 6 (1): 65-82. 
Sihombing, D. T. H. 1997. Ilmu Ternak Babi. Gadjah Mada University Press, Yogyakarta.

Soekartawi. 2002. Analisis Usaha Tani. Universitas Indonesia Press, Jakarta.

Sugiyono. 2010. Metode Penelitian Pendidikan Pendekatan Kuantitatif, Kualitatif, dan R\&D. Bandung. Alfabeta.

Sukanata, IW., A. Astawa, K. M. Budaarsa, dan M. Budiasa,. 2014. Analisis usaha penggemukan babi bali yang menggunakan ransum non konvensional. Neliti 20 (2) : $1-10$.

Sukanata, I W., B. R. T. Putri, Suciani, dan I G. Suranjaya. 2017. Analisis pendapatan usaha penggemukan babi bali yang menggunakan pakan komersial (studi kasus di desa Gerokgak-Buleleng). Neliti 20 (2): 60-63.
Suranjaya. I G., M. Dewantari, I K. W. Parimartha, dan I. W. Sukanata. 2017. Profil usaha peternakan babi skala kecil di desa puhu kecamatan payangan kabupaten gianyar. Majalah Ilmiah Peternakan 20 (2):79-83.

Winarno, W. Wahyu. 2015. Analisis Ekonometrika dan Statistika dengan Eviews. Yogyakarta. UPP STIM YKPN.

Wunda, A. B., A. Keban, dan A. A. Nalle. 2014. Kontribusi usaha ternak babi terhadap pendapatan rumahtangga peternak di kecamatan wewewa barat kabupaten sumba barat daya. Nukleus Peternakan 1 (2): 100107. 